OPEN ACCESS

Edited by:

José Carlos Núñez,

Universidad de Oviedo Mieres, Spain

Reviewed by:

Claudio Longobardi,

University of Turin, Italy

Carbonero Martín Miguel Angel,

University of Valladolid, Spain

*Correspondence:

Jaime Leon

jaime.leon@ulpgc.es

Specialty section:

This article was submitted to

Educational Psychology,

a section of the journal

Frontiers in Psychology

Received: 08 January 2017

Accepted: 15 May 2017

Published: 28 June 2017

Citation:

Leon J, Medina-Garrido E and Núñez JL (2017) Teaching Quality in Math Class: The Development of a

Scale and the Analysis of Its

Relationship with Engagement and Achievement. Front. Psychol. 8:895.

doi: 10.3389/fpsyg.2017.00895

\section{Teaching Quality in Math Class: The Development of a Scale and the Analysis of Its Relationship with Engagement and Achievement}

\author{
Jaime Leon*, Elena Medina-Garrido and Juan L. Núñez \\ Faculty of Educational Sciences, University of Las Palmas de Gran Canaria, Las Palmas, Spain
}

Math achievement and engagement declines in secondary education; therefore, educators are faced with the challenge of engaging students to avoid school failure. Within self-determination theory, we address the need to assess comprehensively student perceptions of teaching quality that predict engagement and achievement. In study one we tested, in a sample of 548 high school students, a preliminary version of a scale to assess nine factors: teaching for relevance, acknowledge negative feelings, participation encouragement, controlling language, optimal challenge, focus on the process, class structure, positive feedback, and caring. In the second study, we analyzed the scale's reliability and validity in a sample of 1555 high school students. The scale showed evidence of reliability, and with regard to criterion validity, at the classroom level, teaching quality was a predictor of behavioral engagement, and higher grades were observed in classes where students, as a whole, displayed more behavioral engagement. At the within level, behavioral engagement was associated with achievement. We not only provide a reliable and valid method to assess teaching quality, but also a method to design interventions, these could be designed based on the scale items to encourage students to persist and display more engagement on school duties, which in turn bolsters student achievement.

Keywords: teacher behavior/beliefs, mathematics, motivation, student engagement, education assessment

\section{INTRODUCTION}

Unlock students' academic potential is a priority for many researchers and practitioners within the educational context (Hulleman et al., 2016). Academic failure has consequences not only during adolescence, when low academic performance results in feelings of failure and eventually to drop out (Valiente et al., 2014), but also in the future, as adults who did not complete their studies are more likely to have health problems and to need social services (Levpuscek et al., 2012; Blankson and Blair, 2016). Within school subjects, mathematics plays a fundamental role for its implication in other school subjects (Gaspard et al., 2015), importance in future social and labor success (Seaton et al., 2014), effects on decisions making in a changing and ambiguous society (Meder and Gigerenzer, 2014), and its relationship with the Gross Domestic Product (OECD, 2010). 
Unfortunately, student math achievement and engagement declines meaningfully all the way through secondary education (Kiemer et al., 2015; Stroet et al., 2015b). Thus, educators at this developmental stage are faced with the challenge of engaging students to learn and achieve. To address this issue, researchers guided by self-determination theory (SDT; Deci and Ryan, 1985, 2000), a broad framework for the study and explanation of human motivation and personality (Liu et al., 2016b), have shown evidence of the role played by the teaching quality (for an overview see: Ryan and Deci, 2009; Núñez and León, 2015). However, knowledge in defining the precise components that lead to an optimal functioning is lacking. Therefore, identification of the key teacher behaviors that raise student performance is a priority (Stroet et al., 2013, 2015a; Hagger and Hardcastle, 2014; Hagger and Chatzisarantis, 2015).

In this article, we begin by describing teaching quality and some of its related concepts. Then, we review researchers' proposals of teaching quality dimensions within SDT. Next, we discuss the benefits of following SDT tenets in the classroom, as well as how engagement might mediate the relationship between teaching quality and academic achievement.

\section{LITERATURE REVIEW}

\section{Teaching Quality}

For the past 40 years, researchers using several frameworks have focused on the characteristics and practices of teachers who appear to be successful in their teaching (Kunter et al., 2013; Wagner et al., 2013). Unfortunately, researchers often use different terms for similar constructs and the same term for different ideas (Marsh et al., 2003; Seaton et al., 2014). For instance, we can use a number of terms to talk about classroom processes related with students learning: Teaching quality (Allen et al., 2011; Fauth et al., 2014), quality of teaching (Hattie, 2009) teaching effectiveness (Marsh and Roche, 1997; Seidel and Shavelson, 2007), instructional quality (Lipowsky et al., 2009; Rjosk et al., 2014), teaching style (Cai et al., 2002; Wentzel, 2002), and instructional style (Jang et al., 2010). Moreover, because teachers' instructional practices refer to variables within the class level (Wagner et al., 2013), other terms used in the literature are classroom quality (Hamre et al., 2014), classroom environment (Day et al., 2015; McLean and Connor, 2015), and classroom management (Arens et al., 2015).

Within SDT, by "teaching quality" we refer to the specific teacher behaviors that supports the student needs of autonomy (feelings of self-determination and not being controlled), competence (feeling efficient and confident in the interactions with the social context), and relatedness (feeling connected and backed up by important others). Several authors have explored the different dimensions of teaching quality (See Ten Cate et al., 2011; Stroet et al., 2013; Liu et al., 2016a). In Table 1 we present a summary of different dimension. In the next sections, we explained them in greater detail.

\section{Autonomy Support}

Autonomy is the feeling of performing an activity selfdetermined, that is, from the highest level of reflection, or to put in other words, emanating from our self, without external pressures, and feelings of being the origin, agent, and cause of beginning and maintaining an activity (Stefanou et al., 2004; Domínguez et al., 2010). At school, students feel autonomous when they believe that school actions are not just an obligation but rather a mean to serve their interests (Wang and Eccles, 2013). When students feel forced to comply with school requirements, they feel controlled and not autonomous. Of course, at school, there are many situations and activities that make students feel controlled and not autonomous, but it is important to remark that this is not an "all or nothing" feeling, and it is in teachers' hands to use different strategies to foster student autonomy.

In this sense, there are different teacher behaviors to support student autonomy in class: (A) Provide meaningful and explanatory rationales. Teachers ought to clarify why class contents and activities are important or useful (Guay et al., 2013; Stroet et al., 2013; Núñez et al., 2015). Explaining why schoolwork is important and relevant helps students to understand how it is in their interest (Assor et al., 2002). Specific teacher behaviors would be to start a lesson by explaining how students might apply class contents in real life or in other subjects, or by explaining how a specific class activity would help them. (B) Nurture inner motivational resources: Teachers could foster student autonomy by reinforcing student interests and developing student curiosity (Stroet et al., 2013; Reeve et al., 2014; Turner et al., 2014; Cheon and Reeve, 2015). A specific teacher behavior might be to explain class contents or frame class activities using interesting and up-to-date examples, or by asking curiosity-inducing questions. (C) Offer meaningful choices: Teachers could diminish student feelings of coercion by providing different options, allowing students to choose something closer to their interests (Núñez et al., 2012; Stroet et al., 2013; Vansteenkiste and Ryan, 2013). A specific teacher behavior could be to offer students the possibility to choose what exercises to do in an exam or to let them pick the topic in a class project. (D) Acknowledge negative feelings: To make students feel less coerced and controlled, teachers could pay attention and understand negative emotions that arise in class. For example, to consider the sadness, worry, or irritation that a student might feel when dealing with an exam or an activity that the student does not know how to solve (Assor et al., 2002; Taylor and Ntoumanis, 2007; Su and Reeve, 2010; Vansteenkiste et al., 2012). A specific teacher behavior could be to approach a student that is sobbing when doing an exam, and explain that it is common to feel anguish, but you know he or she is a hard worker. (E) Participation encouragement: Teachers should try to make students feel part of the class by requesting their opinions or encouraging them to participate in the learning process (Chatzisarantis et al., 2007; Roth et al., 2007; Gillet et al., 2011, 2012; Thapa et al., 2013). A specific teacher behavior might be to ask for the students' opinions about a new topic or welcome student points of view. (F) Non-controlling language: Teachers ought to talk to students in a soft, informational tone using 
TABLE 1 | Teaching quality dimensions and examples.

\begin{tabular}{ll}
\hline Dimension & Example \\
\hline $\begin{array}{l}\text { (A) Provide meaningful and } \\
\text { explanatory rationales }\end{array}$ & $\begin{array}{l}\text { Start a lesson by explaining how } \\
\text { students might apply class contents in } \\
\text { real life }\end{array}$ \\
(B) Nurture inner motivational & Use interesting and up-to-date \\
resources & examples \\
(C) Offer meaningful choices & Let students pick the topic in a class \\
& project \\
(D) Acknowledge negative & Consider the anxiety that a student \\
feelings & might feel when dealing with class \\
& activities \\
(E) Participation encouragement & Ask for the students' opinions about a \\
new topic \\
(F) Non-controlling language & Talk to students in a soft, informational \\
& tone using non-directive language \\
(G) Optimal challenge & Assign different class activities \\
according to the students' levels & Not only value the result, when revising \\
(H) Focus on the process & student class activities \\
(I) Step-by-step instructions & Provide clear instructions and goals \\
(J) Class preparation & Spend time on activities and \\
(K) Positive feedback & explanations before the class \\
(L) Caring & Provide specific information about what \\
& is correct and what could be improve \\
& Pay attention to students' feelings \\
\hline
\end{tabular}

non-directive language and inviting forms instead of controlling forms (you could versus you must), and trying to focus on the didactics rather than on external pressures (Deci et al., 1989; Simons et al., 2005; Hagger et al., 2015).

\section{Competence Support}

Competence is the feeling of accomplishment and effectance when interacting with the environment ( $\mathrm{Ng}$ et al., 2011) or, to put it another way, to know what it means and what it takes to be successful (Wang and Eccles, 2013). Children feel competent at school when they feel capable of achieving learning activities. Therefore, to foster student competence, teachers need to create structured, predictable, contingent, and consistent classrooms (Tessier et al., 2010).

More specifically, teachers need to provide: (A) Optimal challenge. Teachers must take into account the student's level when assigning activities, so students can develop and exercise their capacities (Ryan and Powelson, 1991; Cheon and Reeve, 2015). A specific teacher behavior would be to assign different class activities according to the students' levels. (B) Focus on the process: Teachers need to stress the importance of learning over to solving activities properly without internalizing its meaning and utility (Legault et al., 2006; Tessier et al., 2010; Kusurkar et al., 2011). A specific teacher behavior would be to take into account all of the procedure to solve a problem, and not only value the result, when revising student class activities or exams. Another teacher behavior would be to stress the importance of learning over exam results. (D) Step-by-step instructions: Teachers will provide clear goals and step-by-step instruction when assigning class activities; thus, students could know how to satisfy teacher expectations and achieve the selected academic outcomes (Skinner and Belmont, 1993; Jang et al., 2010; Vansteenkiste et al., 2012; Hospel and Galand, 2016). (D) Class preparation: It is important for teachers to prepare the class well, explain precisely and clearly the class contents, use a good pedagogy during class, and structure the class session to avoid chaos and keep students, as much as possible, on task (Skinner and Belmont, 1993; Legault et al., 2006; Jang et al., 2010; de Naeghel et al., 2014). (E) Positive feedback: Guiding students to the desired goals and outcomes is a key teacher behavior optimally delivered using feedback (Thurlings et al., 2013; Hospel and Galand, 2016). According to Hattie and Timperley (2007), there are four different kinds of feedback, and not all are equally effective: Feedback about the task (FT), used to provide information about right or wrong answers or other specific issues; feedback about the processing of the task (FP), used to provide information about what strategies can be used to acquire a deeper learning; feedback about self-regulation (FR), used to provide information about student self-confidence or effort regulation; and feedback about the student as a person (FS), which includes praising a characteristic at the self and global level (e.g., "good boy"). This last kind of feedback is the least effective. The more specific the feedback is, the more powerful it is. Whereas FR and FP are useful to encourage a deep process and learning of the task, FT is powerful when the information provided leads to better strategies or bolsters self-regulation.

\section{Relatedness Support}

Relatedness is the need to build and maintain positive, meaningful, and lasting relationships (Baumeister and Leary, 1995). Students who feel related with their teacher, feel close, accepted, and backed up by their teacher (León and Liew, 2017). Teachers can foster student relatedness by demonstrating their trust and interest, by being available to them, or by paying attention to their feelings (Stroet et al., 2013). Students who do not feel related to teachers often disengage from class activities (Zee et al., 2013). Yet, when students feel close to and backed up by their teacher, it encourages them to think and learn (Baroody et al., 2014). Students who are more connected to teachers demonstrate positive trajectories of development in academic domains (Hamre and Pianta, 2010). If people are in an environment where they feel cared for and important, it increases the likelihood for the experience of learning out of pleasure and interest (Dietrich et al., 2015).

To sum up, many researchers have addressed the effects of teacher behavior following SDT tenets. However, they have focused not on a global approach but on specific items of each factor: autonomy support, competence support or relatedness support (Stroet et al., 2013). Some authors have focused on an observational basis, while others on self-repot. Observational studies within SDT have not predict strongly (or even not predicted) student academic functioning (Stroet et al., 2013, 2015b). Therefore, and bearing in mind that scales with specific items designed for students to evaluate teaching quality has shown evidence of reliability and validity (Bill and Melinda Gates 
Foundation, 2012; Wallace et al., 2016), in this study, we aim to develop a scale to assess student perceptions of the precise teacher behaviors that influence student performance.

\section{Behavioral Engagement as a Mediator between Teaching Quality and Math Performance}

As mentioned previously, math performance has large implications on students' lives (e.g., job opportunities, decision making, and self-esteem). To optimize student performance, researchers have explored the effect of teaching quality on student performance (Hattie, 2009). For instance, Riconscente (2014), in a year-long study with a sample of 9th- and 10th-grade students, observed that the students' perception of teachers' emphasis on class content interest, relevance, clarity, and caring predicted unique variance in student grades after accounting for demographics variables.

Nonetheless, research analyzing the mechanism by which teacher classroom behaviors affect student performance is still scarce (Ruzek et al., 2014). Therefore, we aim to shed some light on this topic. Skinner et al. (2009) propose that teacher behaviors affect student performance via motivation and engagement. In line with this proposition, Morin et al. (2014) differentiated between effects at both the class and individual level and concluded that students from 4th to 6th grade who perceived their classroom as challenging and their teacher as focused on mastery goals and interested in them, felt more competent, and this, in turn, bolstered their math achievement.

Many variables fall under the umbrella of motivation and engagement (Eccles, 2016); however, an indicator of behavioral engagement (BE) and a predictor of math achievement is effort regulation or effortful persistence, which can be understood as the perceptions of how much investment in time, energy, and work is dedicated to a task or a goal (Liew et al., 2011b). In another words, it is the students' ability to exert effort and to persevere even when doing so is not easy or entertaining (Pintrich and de Groot, 1990). Depending on the theoretical framework, researchers have labeled this construct differently. One approach is the volitional framework (Corno and Kanfer, 1993; Corno, 2004). Experts under this framework would agree to explain it as the tendency to focus attention and direct effort toward goals despite distractions inside and outside schools (Chen, 2002; Pintrich, 2004). From a temperament perspective (Rothbart et al., 2003), the construct of "effortful control" refers to the capacity to regulate behavior and attention willingly (Liew et al., 2011a). Another similar construct is self-control or "grit," the ability to consciously suppress prepotent responses in the service of a higher goal (Duckworth and Seligman, 2005; Duckworth and Steinberg, 2015). From a self-regulated learning perspective (Zimmerman, 2013), effort regulation can be defined as the student's process to manage his or her behavior to achieve a goal; thus, self-regulated students are those who display appropriate levels of effort and persistence to attain their learning goals (Zimmerman, 1990; Zimmerman and Kitsantas, 2014). To sum up, we understand effort regulation as an indicator of engagement, which imply to keep on with school activities even if they are dull or uninteresting.

\section{THE PURPOSE, RESEARCH QUESTION, AND HYPOTHESES OF THE STUDY}

Within SDT research, much remains unknown about the specific and concrete teacher behaviors that foster student academic functioning (Stroet et al., 2013, 2015a; Hagger and Hardcastle, 2014; Hagger and Chatzisarantis, 2015). Therefore, our research question was: can we predict math achievement and engagement via teacher behaviors (teaching quality) asking students?

To answer this question, we depart from two ideas: (1) the individual student's perception about their teacher behaviors might not be a precise indicator, however, if all students in one class perceive their teacher similarly, the average students perception might be a more precise indicator of their teacher behaviors; (2) according to Morin et al. (2014), student responses will vary because of individual perceptions (variance within classes), and because of shared perceptions among students in the same class (variance between classes). Therefore, our first goal was to develop and examine the psychometric properties of a scale for students to evaluate teacher behaviors according to the following dimensions: autonomy support, competence support and relatedness support. Specifically, we hypothesized that the scale would show a sound and robust multidimensional latent structure (Hypothesis 1a), the subscales would be positively associated with each other (Hypothesis $1 \mathrm{~b}$ ), and a significant amount of variance would be due to the grouplevel (Hypothesis 1c).

Our second goal was to test if the scale predicts student engagement and achievement. Drawing on the model of Skinner et al. (2009) and previous studies analyzing the effect of teaching quality on student engagement or motivation (e.g., Fauth et al., 2014; Morin et al., 2014; Longobardi et al., 2016), and the effect of the latter on achievement (Wang et al., 2015), it might be that in classes where the teacher provide meaningful and explanatory rationales, nurture inner motivational resources, offer meaningful choices, acknowledge negative feelings, encourage participation encouragement, use a non-controlling language, provide optimal challenge and stepby-step instructions, focus on the process, prepare the class, provide positive feedback and care about students, they would be more engaged in class, and are more persistent when dealing with school duties. Specifically, we predicted that at the class level, teaching quality would predict student effort regulation (Hypothesis 2a), and in classes where the students, as a whole, are more persistent on class activities, the average grade would be higher (Hypothesis 2b). Last, we predicted, at the individual level, students who persist and make more effort on school activities would achieve higher (Hypothesis 2c).

\section{STUDY 1}

\section{Study 1 Method Participants}

Participants were 548 compulsory secondary students (52\% males) with a mean age of 14.247 years $(S D=1.123)$. The 
students were grouped in 24 classrooms, with a mean number per class of 22.37 ( minimum $=14$; maximum $=30, S D=3.70$ ). Students were in grades 2 to 4 of secondary education, equivalent to 8th to 10th grade in the United States system (grade $8, n=262$, $M_{\text {age }}=13.48$; grade 9, $n=124, M_{\text {age }}=14.38$; grade $10, n=157$, $M_{\text {age }}=15.43$ ). The studied schools comprised a mix of urban and outlying rural public schools with students predominantly from middle-class families. Students attend $4 \mathrm{~h}$ of math lessons per week during the academic year. Students had time enough to know their teacher's behavior in class, because the academic year had started 6 months before the assessment.

\section{Procedure}

Students provided informed consent to take part, and participation was strictly voluntary and confidential. Less than $1 \%$ declined to take part in the evaluation process. During the data collection, researchers administered the initial pool of items to all students in the classroom during March 2015, and provided them with instructions and clarifications if needed to complete the measures.

\section{Measure}

Building upon the SDT framework and previous scales designed to assess teaching quality, a group of research experts on SDT and math teachers designed a pool of 83 items (rated on a 7-point scale, $1=$ strongly disagree to $7=$ strongly agree) to cover specific and concrete teacher behaviors. Specifically, items were considered in relation to the following factors: (A) Meaningful rationales provision: The teacher explains why what students are learning is important or useful. (B) Nurture inner motivational resources: The teacher explains using interesting and up-to-date examples. (C) Offer meaningful choices: The teacher offers different options to students. (D) Acknowledge negative feelings: The teacher understands negative emotions that arise in class. (E) Participation encouragement: The teacher pushes students to take part in class. (F) Controlling language: The teacher talks to students using rigid and directive language. (G) Optimal challenge: The teacher takes into account the student's level when assigning activities. $(\mathrm{H})$ Focus on the process: The teacher stresses the importance of classwork and learning over marks. (I) Step-by-step instructions: The teacher explains precisely and systematically how to proceed with class activities. (J) Classes preparation: The teacher prepares and structures the classes well. (K) Quick feedback: The teacher provides feedback short after the behavior. (L) Self-regulation feedback: The teacher provides feedback about student self-confidence or effort. (M) Specific feedback: The teacher provides concrete and specific feedback. (N) Caring: the teacher looks after and pays attention to the students.

\section{Study 1 Results}

To examine the factor structure, we performed a single-level confirmatory factor analysis (CFA) instead of a multilevel factor analysis because there were too many items for the number of classrooms and students to find a proper solution. Because all variables were ordered categorically, we used the Mean- and
Variance-adjusted Weighted Least-Squares estimation method. The initial CFA with all items showed correlations higher than one between Self-Regulation Feedback and Speed Feedback $(r=1.055)$ and between Providing Meaningful Rationales and Offering Choices $(r=1.027)$, which might be an indicator of misfit. Therefore, to purify the scale (Hair et al., 2010, p. 666), we relied on information from parallel analysis (Horn, 1965; Hayton et al., 2004), exploratory structural equation modeling (ESEM; Asparouhov and Muthén, 2009), and Bayesian structural equation modeling (BSEM; Muthén and Asparouhov, 2012). As recommended by Asparouhov et al. (2015), to generate ideas about model modifications, first we accomplished a BSEM (crossloadings priors with a distribution of mean 0 and variance 0.01 ). Next, we ran an ESEM with all of the items; however, the information provided was quite fuzzy, and we decided to divide the scale and analyze the data, exploring items in close factors based on the BSEM results and theoretical meanings.

We started by running a parallel analysis with the items from the factors: Meaningful Rationales Provision, Nurture Inner Motivational Resources, and Offer Meaningful Choices, concluding that a one-factor solution seemed adequate. This new factor assesses teacher emphasis on relevance, utility, and interests of class contents. Next, we removed items because of low loading values and for theoretical and practical reasons.

Concerning items from the factors: Optimal Challenge, Acknowledge Negative Feelings, Control Language, Provide Optimal Challenge, and Caring, we followed a similar procedure as described previously. We accomplished a parallel analysis, and observed that a five-factor solution was not the best, but there was not much difference in comparison with a lower number of factors. We decided to test a five-factor multilevel CFA and observed that the five-factor model showed an adequate fit: $\chi^{2}(547,1034)=3026.221(p=0.00)$, RMSEA $=0.059$, $\mathrm{SRMR}_{\text {within }}=0.056, \mathrm{SRMR}_{\text {between }}=0.129, \mathrm{CFI}=0.962$, and $\mathrm{TLI}=0.958$. Thus, we opted for this five-factor option; next, we removed items because of low loading values and for theoretical and practical reasons.

Finally, we ran a parallel analysis with items from the following factors: Focus on the Process, Class Preparation, Step-By-Step Instruction, and all Feedback items. We observed that three factors seem a good statistical and theoretical solution, and that items from Step-By-Step Instruction and Class tended to load on the same factor, something understandable, as both assess the teacher structure in the classroom. The next step was to remove items from this factor because of low loadings values and for theoretical and practical reasons.

Once we had the final 53 items and 9 factors, we ran a multilevel CFA (MCFA); the $\chi^{2}$ value and fit indexes were $\chi^{2}(547,2578)=4583.151(p=0.00)$, RMSEA $=0.038$, $\mathrm{SRMR}_{\text {within }}=0.052, \mathrm{SRMR}_{\text {between }}=0.121, \mathrm{CFI}=0.980$, and $\mathrm{TLI}=0.979$. Loadings at the individual level ranged from 0.431 to 0.798 . With regard to correlations, at the within level, they ranged from 0.846 (Caring with Positive Feedback) to 0.261 (Controlling Language with Focus on the Process), and at the classroom level, they ranged from 1 (Optimal Challenge with Teaching for Relevance) to 0.755 (Controlling Language with Teaching for Relevance). 
To examine reliability, instead of Cronbach's alpha, we used McDonald's Omega (McDonald, 1999) because the former requires factor loadings to be equal for all items (McNeish, 2017) and data to be continuous (Elosua and Zumbo, 2008). Further, McDonald's Omega has shown evidence of better accuracy compared with Cronbach's alpha (Revelle and Zinbarg, 2009). McDonalds' values should be interpreted in a similar fashion as Cronbach's alpha is: values above 0.70 to 0.80 are indicators of reliability. Table 2 shows that McDonald's Omega varied from 0.650 (Focus on the Process) to 0.893 (Positive Feedback).

To examine the average agreement between students, or the proportion of the total variance at the group level, we estimated intraclass correlation (ICC1). Values close to 1 indicate that all of the variance is due to the class, whereas values close to 0 , indicate that the variability is due to the subjects and not to the group. ICC1 varied between 0.415 for Acknowledge negative feelings and 0.013 for Focus on the Process (Table 2). Finally, to test the reliability as a group construct, we estimated ICC2. Values close to one are evidence that students in the same classroom share the same feelings or thoughts, whereas values close to one indicate that the construct assessed is independent among students (Morin et al., 2014). ICC2 varied from 0.942 (Acknowledge Negative Feelings) to 0.225 (Focus on the process).

\section{Study 1 Discussion}

The first aim of the study was to develop, purify, and examine the psychometric properties of a scale to teacher behaviors according to SDT tenets asking students. We hypothesized that the scale would show a sound and robust multidimensional latent structure, the subscales would be positively associated with each other, and a significant amount of variance would be due to group-level variance.

We developed a pool of 83 items designed to assess 14 factors. After a purifying process, we had a 53 items and 9 factor scale. The factors are teaching for relevance, acknowledge negative feelings, participation encouragement, controlling language, optimal challenge, focus on the process, class structure, positive feedback, and caring. The reduction from 14 to 9 factors was achieved because items designed to measure different feedback factors were merged in one factor. Similarly, the factors meaningful rationales provision, nurture inner motivational resources, and offer meaningful choices, were merged in a unique factor called teaching for relevance. Likewise, items from stepby-step instruction and class preparation were merged into one factor. These results are in line with previous research (Assor et al., 2002; Wang and Eccles, 2013), suggesting that students feel autonomous when they do not feel coerced. Thus, if teachers offer different options but none satisfy their interests or are not useful for students, they would still not feel autonomous. It is not just offering choices or options, but also opening up the range of meaningful possibilities to cover student interests and priorities what matters. Therefore, it seems likely that the factor to assess is teaching for relevance, meaning that the teacher relies on useful and interesting class content and activities, to provide different options to reach the majority of students. We also merged in one-factor (class structure) items designed to tap two factors: Step-by-step instruction and class preparation.

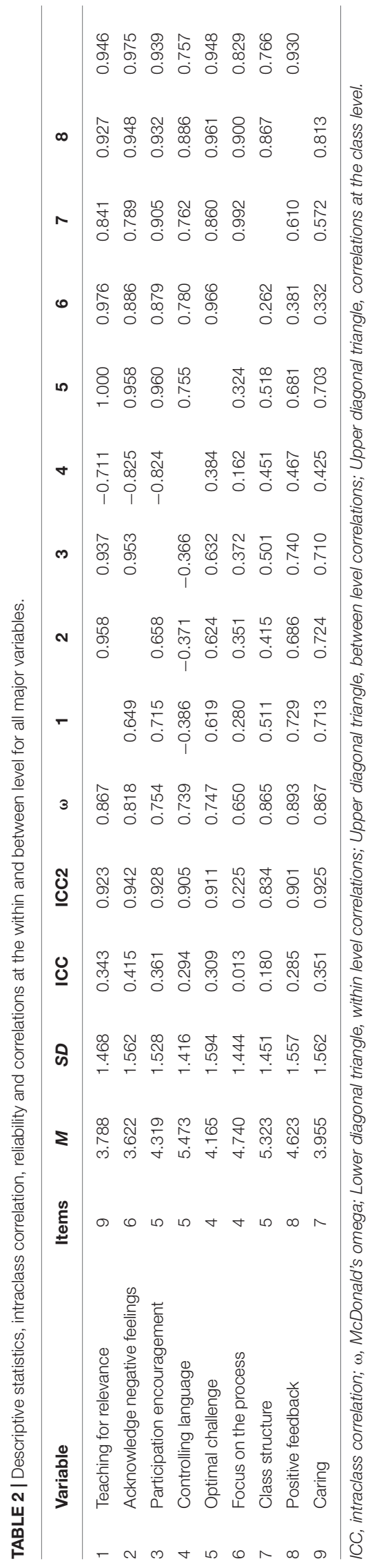


Step-by-step instructions refer to if teacher explains activities and contents clearly, and class preparation if the teacher knows the class content and organize the class well. Thus, although we hypothesized that students would understand them as two different factors, students seem to perceive it as one factor. It might be that if teachers prepare the classes, they also prepare the activities.

With regard to the hypothesis of observing a sound and robust multidimensional latent structure, reliabilities were adequate, and results of the MCFA revealed that the data fit a ninefactor model, with strong loadings on the intended factors, and correlations between factors. At the individual level, correlations values were moderate, but at the within level, higher values were observed, which is in line with previous studies assessing teaching quality: for instance, Fauth et al. (2014) observed a correlation of 0.89 between cognitive activation and supportive climate, and Morin et al. (2014) observed a correlation of 0.92 between mastery goal structure and challenge. Fast et al. (2010) and Morin et al. (2014) posit that these high correlations might be because factors fall under a common denominator: the teaching style, so it makes sense that student perception of teacher behavior represents a higher-order factor.

We expected that a meaningful part of the variance would be due to the class level variance, and in line with previous studies assessing teacher or class behaviors (Fauth et al., 2014; Decristan et al., 2015). We observed that the scale seems to capture the group nature of a class evaluation. To sum up, these results provided support for sound psychometric properties, supporting the factorial validity of the scale. However, we need evidence that the purified scale fits the data in another sample and predicts student engagement and achievement.

\section{STUDY 2}

\section{Study 2 Method \\ Participants}

Participants were 1555 compulsory secondary students (51\% females; mean age $=15.30$ years, $S D=1.12$ ) grouped in 82 classrooms from nine schools, in grades 2 to 4 of secondary education, equivalent to 8 th to 10 th grade in the United States system (Grade 8, $n=588, M_{\text {age }}=13.94$; Grade 9, $n=484$, $M_{\text {age }}=15.01 ;$ Grade $\left.10, n=483, M_{\text {age }}=16.19\right)$. The studied schools comprised a mix of urban and outlying rural public schools with students predominantly from middle-class families. Students attend to $4 \mathrm{~h}$ of math lessons per week during the academic year. They had time enough to know their teacher's behavior in class, because the academic year had started 6 months before the assessment.

\section{Procedure}

We followed a similar procedure as in the previous study. Students provided informed consent to participate, and partaking was strictly voluntary and confidential. Less than $1 \%$ declined to take part in the evaluation process. During the data collection, in May 2015, researchers administered the instruments to students in their classrooms and provided students with instructions and clarifications if needed to complete the measures. At the end of the school year in June, we obtained the student final course grades in mathematics from school records. To maintain anonymity, the school provided records without the name, just the class and the birthdate of each student, which we later linked with the questionnaire of each student. However, in the same class, 5 times three students were born on the same day, and 26 times two students were born on the same day; therefore, we could not match grades with questionnaires for these 67 students.

\section{Measures}

To analyze scale reliability, we computed McDonald's Omega. To estimate how much variance was due to group-level variance, we estimated ICC1. To examine the reliability of the measure as a group indicator we calculated ICC2. Finally, to test the factor structure, we ran a MCFA.

\section{Teaching quality}

We used the 53-item scale described in the previous study. The scale assesses nine factors: (A) Teaching for relevance: the teacher uses useful and interesting class contents and activities. (B) Acknowledge negative feelings: The teacher understands negative emotions arisen in class. (C) Participation encouragement: The teacher pushes students to take part in class, by asking questions or soliciting students' opinions. (D) Controlling language: The teacher talks to student in rigid and directive language. (E) Optimal challenge: The teacher takes into account student level when assigning activities. (F) Focus on the process: The teacher stresses the importance of classwork and learning over marks. (G) Classes structure: The teacher prepares and structures the classes and activities well. (H) Positive feedback: The feedback provided is quick, positive, and specific. (I) Caring: The teacher looks after and pays attention to students. Reliability ranged from 0.919 (Positive Feedback) to 0.804 (Focus on the Process). ICC1 ranged from 0.545 (Teaching for Relevance) to 0.342 (Focus on the Process). ICC2 ranged from 0.957 (Teaching for Relevance) to 0.905 (Focus on the Process) (Table 3). Finally, concerning the MCFA, the $\chi^{2}$ value and fit indexes were $\chi^{2}(1524,2578)=19843.661(p<0.001)$, RMSEA $=0.067$, $\mathrm{SRMR}_{\text {within }}=0.046, \mathrm{SRMR}_{\text {between }}=0.054, \mathrm{CFI}=0.966$, and $\mathrm{TLI}=0.964$. All items are listed in the Supplemental Material.

\section{Effort regulation}

Student effort regulation was assessed using four items from the effort regulation subscale of the Motivated Strategies for Learning Questionnaire (Pintrich et al., 1993) on a 7-point scale $(1=$ strongly disagree to $7=$ strongly agree $)$. Sample items included "When work is difficult, I either give up or study only the easy parts." All items on this measure have demonstrated adequate reliability $(\omega=0.74)$ in prior research (León et al., 2015) and in the present study $(\omega=0.716)$. ICC1 was 0.168 , and ICC2 was 0.783 . With regard to the MCFA, residual correlation between two of the four items that were worded in a similar way was allowed; the $\chi^{2}$ value and fit indexes were $\chi^{2}(1524,1)=6.471(p=0.039)$, RMSEA $=0.038$, $\mathrm{SRMR}_{\text {within }}=0.010, \mathrm{SRMR}_{\text {between }}=0.013, \mathrm{CFI}=0.999$, and $\mathrm{TLI}=0.994$. 


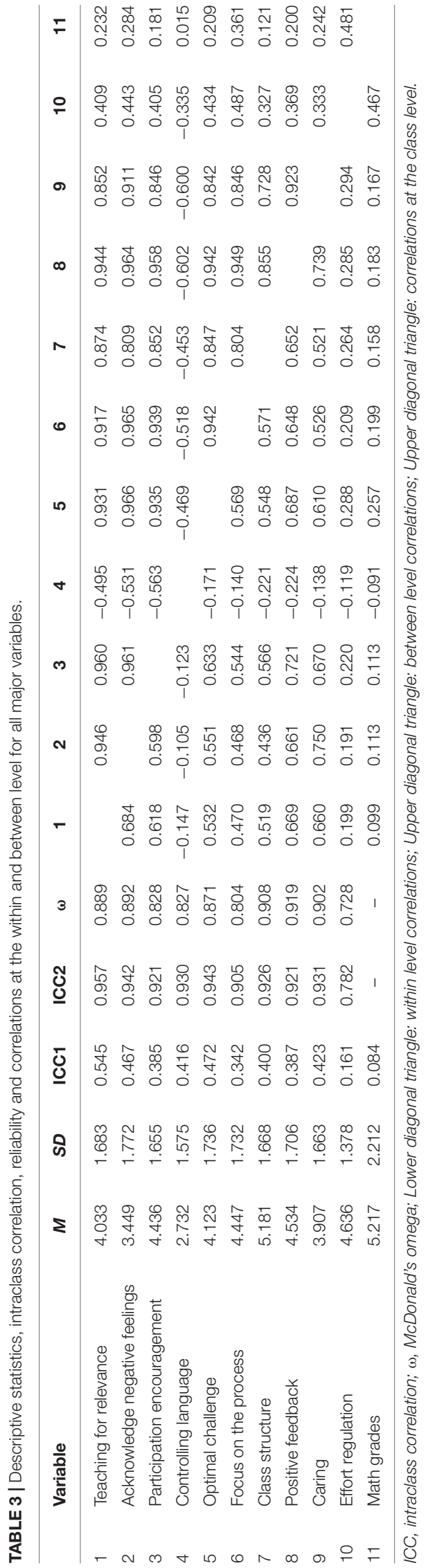

\section{Math grades}

Student math performance was indexed by student final course grades in mathematics, which we obtained from the official high school records. Unlike in the United States or United Kingdom, where it is common to assess students using standardized test, in Spain we rely more on school grades assigned by teachers, because there is not such a variety of standardized tests. Teachers have to assign grades using rubrics implemented by the Government based on student knowledge, skills and work in class and at home.

These grades have real-world significance on student academic standing and progress in grade school (Thorsen and Cliffordson, 2012; Simões and Alarcão, 2014; Sánchez-Pérez et al., 2015). Actually, in Spain, students choose different tracks and even different universities based on their high school grades. Grades were coded as 1 being the lowest and 10 being the highest possible mark. Teachers give an average score based on student's skills, knowledge, and homework, as required by Spanish curriculum.

\section{Data Analysis}

Descriptive analyses and correlations between major variables, at the within and between level, were conducted. Next, we tested the second hypothesis by running a multilevel structural equation model (MSEM), where at the individual level, effort regulation predicted math performance, and at the class level teaching quality predicted math performance via effort regulation. To test if effort regulation mediated the effect of teaching quality on math performance, we added, in a nested MSEM, a direct effect from teaching quality to math performance; we can conclude that, if this direct effect is not significantly different from zero and the fit of the two-nested model is not different, effort regulation is a mediational variable. We handled missing data using the full information maximum-likelihood method with the Meanadjusted Weighted Least-Squares estimator (Asparouhov and Muthén, 2010).

\section{Study 2 Results Descriptive Analysis and Correlations at the within and the between Level}

Descriptive statistics (means and standard deviations) and correlation for all major variables are displayed in Table 3. The means varied between 2.732 (Controlling Language) and 5.217 (math grades), and standard deviations between 1.378 (Effort Regulation) and 2.212 (math grades). With regard to correlations, at the within level, they ranged from 0.687 (Optimal Challenge with Positive Feedback) to -0.091 (Controlling Language with math grades), and at the between level, they ranged from 0.965 (Acknowledge Negative Feelings and Optimal Challenge) to 0.015 (Controlling Language with math grades).

\section{Multilevel Model}

The $\chi^{2}$ test and fit indexes for the MSEM $\chi^{2}(1504,3170)$ $=23506.247(p=0.00)$, RMSEA $=0.065, \mathrm{SRMR}_{\text {within }}=0.052$, $\mathrm{SRMR}_{\text {between }}=0.087, \mathrm{CFI}=0.962$, and TLI $=0.961$. In Figure 1, we can see, that, at the within level, all Teaching Quality factors loaded on a higher-order factor. Effort Regulation predicted math grades $(\beta=0.528$; $\mathrm{SE}=0.036 ; p<0.001)$, explaining $28 \%$ of its 


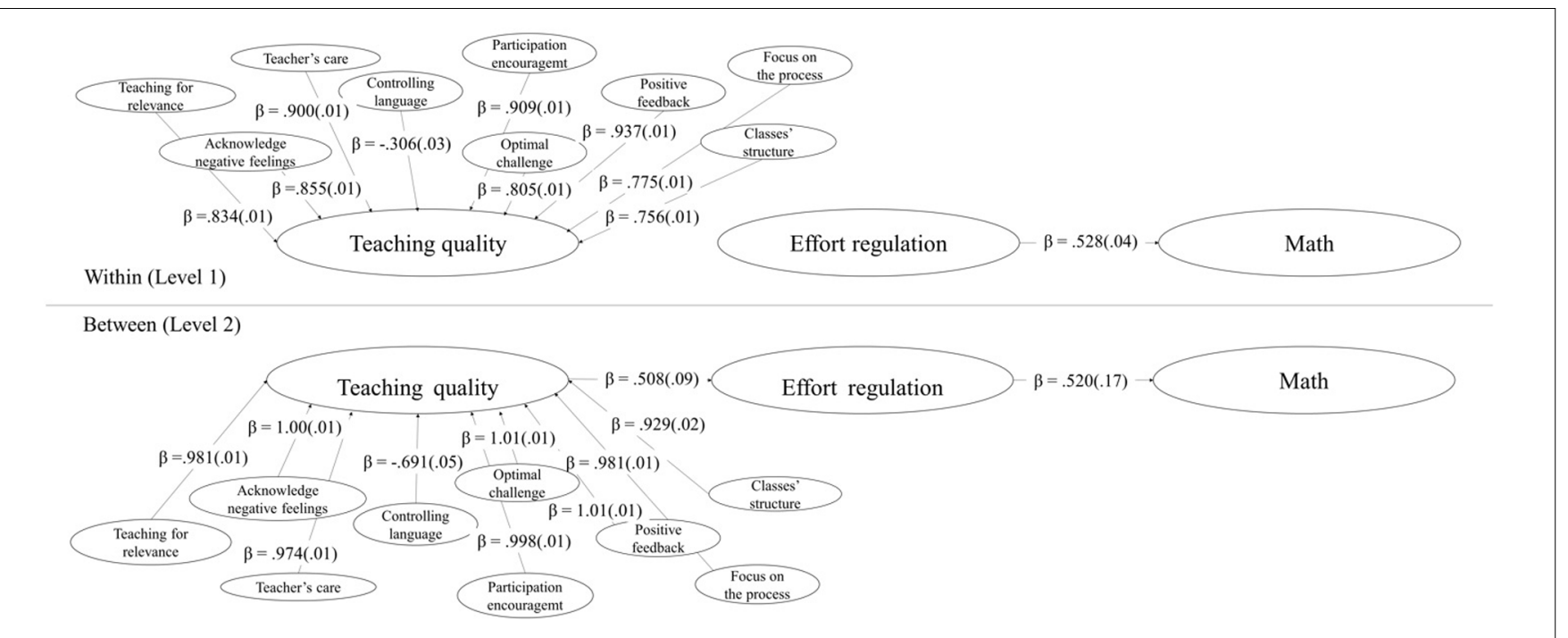

FIGURE 1 | Multilevel structural equation model. All effects are significant $(p<0.001)$. Standard errors between parentheses.

variance. Whereas at the between level, every Teaching Quality factors loaded on its factor, and Teaching Quality predicted Effort Regulation $(\beta=0.508$; $\mathrm{SE}=0.097 ; p<0.001)$, and this, in terms, math grades $(\beta=0.520$; $\mathrm{SE}=0.171 ; p<0.001)$; explaining $26 \%$ and $27 \%$ of its variance, respectively.

With regard to the mediational effect at the between level of Effort Regulation, in the relationship between Teaching Quality and math grades, we compared the above mentioned MSEM with a MSEM with an additional path from math grades to Teaching Quality. The $\chi^{2}$ test and fit indexes for this MSEM were $\chi^{2}(1527,3169)=23549.585(p=0.00)$, $\mathrm{RMSEA}=0.065, \mathrm{SRMR}_{\text {within }}=0.052, \mathrm{SRMR}_{\text {between }}=0.087$, $\mathrm{CFI}=0.962$, and TLI $=0.961$. The $\chi^{2}$ test (adjusting for the correction factor) comparing both models was not significant: $\Delta \chi^{2}(1527,1)=2.921(p>0.05)$, and the direct effect from Teaching Quality to math grades was not different from zero $(\beta=-0.076 ; \mathrm{SE}=0.146 ; p=0.66)$. Therefore, we can conclude that, at the between level, Effort Regulation mediates the relationship between Teaching Quality and math achievement.

\section{Study 2 Discussion}

This study provides support for the hypotheses tested. At the between level, teaching quality was found to be a predictor of effort regulation (Hypothesis 2a): higher grades were observed in classes where students, as a whole, displayed more effort regulation (Hypothesis 2b). At the within level, students who showed more effort regulation on school activities achieved higher grades (Hypothesis 2c). Therefore, Study 2 provides more support of the scale developed to assess teaching quality.

\section{Teaching Quality and Behavioral Engagement}

With regard to Hypothesis 2a, we observed that when the students, as a whole, perceived that their teacher provided quality teaching, more BE was displayed. This in line with the model of Skinner et al. (2009), who propose that teaching quality might predict student academic functioning (e.g., motivation, engagement, and achievement). In this research, we have conceptualized "quality teaching" as when the teacher conducts lessons with useful and interesting class contents and activities (teaching for relevance); understands negative emotions that arise in class (acknowledge negative feelings); pushes students to take part in class (participation encouragement); talks to student in non-controlling and attuned language (controlling language); takes into account students' levels when assigning activities (optimal challenge); stresses the importance of classwork and learning over marks (focus on the process); prepares and structures the classes and activities well (class structure); provides feedback that is quick, positive, and specific (positive feedback); and looks after and pays attention to students (caring). It seems that specific teacher behaviors, such as calming down students when they are nervous doing an exam or bearing in mind the students' levels when assigning class activities, promote students' persistence when studying math. Effort regulation is necessary for students to achieve many school activities and to pay attention in class and perform when there are some more appealing activities to do (watching TV or playing videogames). Thus, educators who provide a quality teaching, as conceptualized in this research, are providing students with prerequisites for persisting on school activities.

\section{Behavioral Engagement and Math Grades}

In line with hypotheses $2 \mathrm{~b}$ and $2 \mathrm{c}$, the multilevel model showed that $\mathrm{BE}$ had predictive power for grades. At the individual level, these results, in addition to those from others researchers (Duckworth et al., 2012; Hofer et al., 2012), suggest that students get better grades if they gain the capacity to persist studying even when they find it dull or prefer to do something else. We observed similar results at the class level, where higher grades are observed in classes where the students, as a whole, display more effort regulation. Thus, we agree with Veronneau et al. (2014) that educators who want students to achieve as high as possible 
should pay attention to students and try to foster effort regulation in them.

\section{Indirect Effect of Behavioral Engagement between Teaching Quality and Math Grades}

Our results indicate that effort regulation, as an indicator of $\mathrm{BE}$, is one mechanism that mediates the link between teaching quality and math performance. These results are in line with the model of Skinner et al. (2009). Other researchers have also focused on the effect of teaching quality on math performance. For example, Kunter et al. (2013), assessing mainly teachers instead of students, observed that pedagogical content knowledge and teacher enthusiasm predicted math grades via the use of applied math problems and classroom disruption and discipline. Morin et al. (2014) also focused on teaching quality and math performance. They observed that self-efficacy mediated the relationship between those two variables. Our study adds to the previous studies a stronger prediction of math grades. Whereas Kunter et al. (2013) explained $13 \%$ of math achievement variance, and Morin et al. (2014) reported and effect size of 0.15 , we explained $27 \%$ of the variance at the between and $28 \%$ at the within level. Moreover, in this research, we assessed multiple specific teacher behaviors, which researchers or practitioners could use to design useful interventions to promote student achievement.

\section{GENERAL DISCUSSION}

Educators face the challenge of engaging students to learn and achieve during middle and high school math lessons. Teaching quality during class have important influence on student functioning. However, within SDT, the precise teacher behaviors that lead to optimal functioning are not well defined. Therefore, in the first study, we proposed an instrument to assess specific and concrete teacher behaviors, and in the second study, we identified a mechanism by which these teacher behaviors predict math achievement.

In study 1, we developed a scale to assess teaching quality with nine factors to capture specific and concrete teacher behaviors. The developed scale provided evidence of reliability and factorial validity. However, we needed evidence that the scale fit the ninefactor structure in another sample, and that it predicts student engagement and achievement.

Study 2 builds on existing literature that underscores the importance of teaching quality as key predictors of educational attainment (Skinner et al., 2009; Fauth et al., 2014). We observed that effort regulation mediated the relationship between teaching quality and grades. It is important to highlight that it could be that the educators with a positive quality teaching might assign higher grades to students. However, as shown in the results section, the direct effect of teaching quality on math grades, controlling for effort regulation, was not different from zero because effort regulation is the linking variable between teaching quality and math achievement. To put it different, with the precaution of not making causal claims, it seems that teaching quality promotes students' effort regulation, and this, in turn, promotes math achievement. Thus, it seems as it is not that teachers with a better teaching quality assign higher grades, but, that these teachers move students to put more effort on their school activities, which, in turn, leads to higher grades.

\section{Strengths and Limitations}

Our study included a number of strengths: We conducted two separate studies to analyze scale psychometric properties, and in the second study, we included two waves of data. In the first one, we assessed teacher behavior and student effort regulation, whereas in the second, we collected math grades 1 month later.

Student ratings of teacher behavior assess the typical teacher performance along the course, and have been proposed as an accepted method to evaluate teaching methods (Wagner et al., 2013; OECD, 2014; Wallace et al., 2016). Usually, teacher observation assesses just one or more days of class behaviors, where the teacher might strive to teach as "good as possible," but we are aware that this observational information might help to grasp a bigger picture of the classroom. Therefore, future studies could gather observational information of teaching quality based on the nine factors proposed in this study.

One limitation regarding study 1 is the limited sample size. This fact, among the high correlations between different factors, precluded us of reaching convergence in the MCFA. Subsequently, we aimed to purify the scale accomplishing an ESEM, unfortunately, results were fuzzy, that is, we did not have information about the optimal number of factors nor about the relationship between items and factors. Therefore, we proceeded to a step-by-step procedure based on the BSEM results and theoretical information. Although this procedure might look arbitrary, we believe that the proposed scale has theoretical foundations and evidence of reliability and validity to warrant its use.

It is also important to stress that this research has been conducted in Spain. In this country, and other European countries, grades are of ultimate importance: students based on their academic grades choose track and, later on, University. Thus, in Spain grades is a variable of ultimate importance for student life. Researchers in other countries, such as United States or United Kingdom, could assess the impact of the scale on other variables such as the SAT, ACT or GCSE.

Finally, the effects of teaching quality on student learning can be diverse. As pointed out by Seidel and Shavelson (2007), some teacher behaviors might have short-term effects (e.g., interest and enthusiasm), whereas others might have longer effects (e.g., motives to study and study strategies). Therefore, it might be interesting to study the effect on different variables, beyond effort regulation and math grades. In a similar fashion, although the study was designed under the SDT umbrella we did not assess key variables such as autonomy, competence or relatedness, because our goal was not to predict these three psychological variables, but to predict behavioral indicators such as student $\mathrm{BE}$ and achievement. However, we believe that it could be interesting for future research to test the relationship between the teaching quality factors and autonomy, 
competence or relatedness. Finally, we believe that it could be interesting to test the effect of school variables such as percentage of students receiving free and reduced-price meals or school climate (Konold, 2016) on teaching quality.

\section{CONCLUSION}

In this study, we aimed to shed some light in the discovery of new path to optimize students' math achievement. Therefore, we focused on a variable amenable to intervention: teaching quality. We provide a reliable and valid instrument for students to assess specific and concrete teachers' behaviors during class, which we grouped under the label teaching quality. The findings of this study have implications for practitioners and researchers. The former could use the developed scale to assess their teaching quality, while researchers could design interventions based on the scale items to promote student persistence

\section{REFERENCES}

Allen, J. P., Pianta, R. C., Gregory, A., Mikami, A. Y., and Lun, J. (2011). An interaction-based approach to enhancing secondary school instruction and student achievement. Science 333, 1034-1037. doi: 10.1126/science.1207998

Arens, A. K., Morin, A. J. S., and Watermann, R. (2015). Relations between classroom disciplinary problems and student motivation: achievement as a potential mediator? Learn. Instr. 39, 184-193. doi: 10.1016/j.learninstruc.2015. 07.001

Asparouhov, T., and Muthén, B. O. (2009). Exploratory structural equation modeling. Struct. Equ. Modeling 16, 397-438. doi: 10.1080/107055109030 08204

Asparouhov, T., and Muthén, B. O. (2010). Weighted Least Squares Estimation with Missing Data. Available at: http://www.statmodel.com/download/ GstrucMissingRevision.pdf

Asparouhov, T., Muthén, B. O., and Morin, A. J. S. (2015). Bayesian structural equation modeling with cross-loadings and residual covariances: comments on Stromeyer et al. J. Manag. 41, 1561-1577. doi: 10.1177/01492063155 91075

Assor, A., Kaplan, H., and Roth, G. (2002). Choice is good, but relevance is excellent: autonomy-enhancing and suppressing teacher behaviours predicting students' engagement in schoolwork. Br. J. Educ. Psychol. 72, 261-278. doi: $10.1348 / 000709902158883$

Baroody, A. E., Rimm-Kaufman, S. E., Larsen, R. A., and Curby, T. W. (2014). The link between responsive classroom training and student-teacher relationship quality in the fifth grade: a study of fidelity of implementation. School Psych. Rev. 43, 69-85.

Baumeister, R. F., and Leary, M. R. (1995). The need to belong: desire for interpersonal attachments as a fundamental human motivation. Psychol. Bull. 117, 497-529. doi: 10.1037/0033-2909.117.3.497

Bill and Melinda Gates Foundation (2012). Asking Students About Teaching: Student Perception Surveys and their Implementation. Seattle, WA: Measures of Effective Teaching (MET) Project.

Blankson, A. N., and Blair, C. (2016). Cognition and classroom quality as predictors of math achievement in the kindergarten year. Learn. Instr. 41, 32-40. doi: 10.1016/j.learninstruc.2015.09.004

Cai, Y., Reeve, J., and Robinson, D. T. (2002). Home schooling and teaching style: comparing the motivating styles of home school and public school teachers. J. Educ. Psychol. 94, 372-380. doi: 10.1037//0022-0663.94.2.372

Chatzisarantis, N. L. D., Hagger, M. S., and Smith, B. (2007). Influences of perceived autonomy support on physical activity within the theory of planned behavior. Eur. J. Soc. Psychol. 37, 934-954. doi: 10.1002/ejsp.407

Chen, C. S. (2002). Self-regulated learning strategies and achievement in an introduction to information systems course. Inf. Technol. Learn. Perform. J. 20, $11-25$. and effort on school duties, which in turn, bolsters student achievement.

\section{ETHICS STATEMENT}

This study was carried out with written informed consent from all subjects. All subjects gave written informed consent in accordance with the Declaration of Helsinki. The protocol was approved by the University of Las Palmas de Gran Canaria.

\section{AUTHOR CONTRIBUTIONS}

Conception or design of the work: JL. Data collection: JL, EM-G. Data analysis and interpretation: JL, EM-G. Writing the manuscript: JL, EM-G. Edit the manuscript: JN. Final approval of the version to be published: JL, EM-G, JN.

Cheon, S. H., and Reeve, J. (2015). A classroom-based intervention to help teachers decrease students' amotivation. Contemp. Educ. Psychol. 40, 99-111. doi: 10. 1016/j.cedpsych.2014.06.004

Corno, L. (2004). Introduction to the special issue work habits and work styles: volition in education. Teach. Coll. Rec. 106, 1669-1694. doi: 10.1111/j.14679620.2004.00400.x

Corno, L., and Kanfer, R. (1993). The role of volition in learning and performance. Rev. Res. Educ. 19, 301-341. doi: 10.3102/0091732X019001301

Day, S. L., Connor, C. M., and Mcclelland, M. M. (2015). Children's behavioral regulation and literacy: the impact of the fi rst grade classroom environment. J. Sch. Psychol. 53, 409-428. doi: 10.1016/j.jsp.2015.07.004

de Naeghel, J., van Keer, H., and Vanderlinde, R. (2014). Strategies for promoting autonomous reading motivation: a multiple case study research in primary education. Frontline Learn. Res. 3, 83-101.

Deci, E. L., Connell, J. P., and Ryan, R. M. (1989). Self-Determination in a work organization. J. Appl. Psychol. 74, 580-590. doi: 10.1037//0021-9010. 74.4.580

Deci, E. L., and Ryan, R. M. (1985). Intrinsic Motivation and Self-Determination in Human Behavior. New York, NY: Plenum. doi: 10.1007/978-1-4899-2271-7

Deci, E. L., and Ryan, R. M. (2000). The "What" and "Why" of Goal Pursuits: human needs and the self-determination of behavior. Psychol. Inq. 11, 227-268. doi: 10.1207/S15327965PLI1104_01

Decristan, J., Klieme, E., Kunter, M., Hochweber, J., Buttner, G., Fauth, B., et al. (2015). Embedded formative assessment and classroom process quality: how do they interact in promoting science understanding? Am. Educ. Res. J. 52, 1133-1159. doi: 10.3102/0002831215596412

Dietrich, J., Dicke, A.-L., Kracke, B., and Noack, P. (2015). Teacher support and its influence on students' intrinsic value and effort: dimensional comparison effects across subjects. Learn. Instr. 39, 45-54. doi: 10.1016/j.learninstruc.2015. 05.007

Domínguez, E. G., Martín, P., Martín-Albo, J., Núñez, J. L., and León, J. (2010). Translation and validation of the Spanish version of the "Echelle de Satisfaction des Besoins Psychologiques" in the sports context. Span. J. Psychol. 13, 1010-1020. doi: $10.1017 /$ S1138741600002651

Duckworth, A. L., Quinn, P. D., and Tsukayama, E. (2012). What no child left behind leaves behind: the roles of IQ and self-control in predicting standardized achievement test scores and report card grades. J. Educ. Psychol. 104, 439-451. doi: $10.1037 / \mathrm{a} 0026280$

Duckworth, A. L., and Seligman, M. E. P. (2005). Self-discipline outdoes IQ in predicting academic performance of adolescents. Psychol. Sci. 16, 939-944. doi: 10.1111/j.1467-9280.2005.01641.x

Duckworth, A. L., and Steinberg, L. (2015). Unpacking self-control. Child Dev. Perspect. 9, 32-37. doi: 10.1111/cdep.12107

Eccles, J. S. (2016). Engagement: Where to next? Learn. Instr. 43, 71-75. doi: 10.1016/j.learninstruc.2016.02.003 
Elosua, P., and Zumbo, B. D. (2008). Reliability coefficients for ordinal response scales. Psicothema 20, 896-901. doi: 10.1111/vde.12193

Fast, L. A., Lewis, J. L., Bryant, M. J., Bocian, K. A., Cardullo, R. A., Rettig, M., et al. (2010). Does math self-efficacy mediate the effect of the perceived classroom environment on standardized math test performance? J. Educ. Psychol. 102, 729-740. doi: 10.1037/a0018863

Fauth, B., Decristan, J., Rieser, S., Klieme, E., and Büttner, G. (2014). Student ratings of teaching quality in primary school: dimensions and prediction of student outcomes. Learn. Instr. 29, 1-9. doi: 10.1016/j.learninstruc.2013.07.001

Gaspard, H., Dicke, A.-L., Flunger, B., Brisson, B. M., Haefner, I., Nagengast, B., et al. (2015). Fostering adolescents'value beliefs for mathematics with a relevance intervention in the classroom. Dev. Psychol. 51, 1226-1240. doi: 10. $1037 /$ dev0000028

Gillet, N., Berjot, S., Vallerand, R. J., and Amoura, S. (2012). The role of autonomy support and motivation in the prediction of interest and dropout intentions in sport and education settings. Basic Appl. Soc. Psychol. 34, 278-286. doi: 10.1080/01973533.2012.674754

Gillet, N., Vallerand, R. J., and Lafrenière, M.-A. K. (2011). Intrinsic and extrinsic school motivation as a function of age: the mediating role of autonomy support. Soc. Psychol. Educ. 15, 77-95. doi: 10.1007/s11218-011-9170-2

Guay, F., Ratelle, C. F., Larose, S., Vallerand, R. J., and Vitaro, F. (2013). The number of autonomy-supportive relationships: are more relationships better for motivation, perceived competence, and achievement? Contemp. Educ. Psychol. 38, 375-382. doi: 10.1016/j.cedpsych.2013.07.005

Hagger, M. S., and Chatzisarantis, N. L. D. (2015). The trans-contextual model of autonomous motivation in education: conceptual and empirical issues and meta-analysis. Rev. Educ. Res. 86, 360-407. doi: 10.3102/0034654315585005

Hagger, M. S., and Hardcastle, S. J. (2014). Interpersonal style should be included in taxonomies of behavior change techniques. Front. Psychol. 5:254. doi: 10.3389/ fpsyg.2014.00254

Hagger, M. S., Sultan, S., Hardcastle, S. J., and Chatzisarantis, N. L. D. (2015). Perceived autonomy support and autonomous motivation toward mathematics activities in educational and out-of-school contexts is related to mathematics homework behavior and attainment. Contemp. Educ. Psychol. 41, 111-123. doi: 10.1016/j.cedpsych.2014.12.002

Hair, J. F., Black, W. C., Babin, B. J., and Anderson, R. E. (2010). Multivariate Data Analysis, 7th Edn. New York, NY: Prentice Hall.

Hamre, B. K., Hatfield, B. E., Pianta, R. C., and Jamil, F. (2014). Evidence for general and domain-specific elements of teacher-child interactions: associations with preschool children's development. Child Dev. 85, 1257-1274. doi: 10.1111/cdev. 12184

Hamre, B. K., and Pianta, R. C. (2010). "Classroom environments and developmental processes," in Handbook of Research on Schools, Schooling and Human Development, eds J. L. Meece and J. S. Eccles (New York, NY: Routledge), 25-41.

Hattie, J. (2009). Visible Learning: A Synthesis of Over 800 Meta-Analyses Relating to Achievement. New York, NY: Routledge.

Hattie, J., and Timperley, H. (2007). The power of feedback. Rev. Educ. Res. 77, 81-112. doi: $10.3102 / 003465430298487$

Hayton, J. C., Allen, D. G., and Scarpello, V. (2004). Factor retention decisions in exploratory factor analysis: a tutorial on parallel analysis. Organ. Res. Methods 7, 191-205. doi: 10.1177/1094428104263675

Hofer, M., Kuhnle, C., Kilian, B., and Fries, S. (2012). Cognitive ability and personality variables as predictors of school grades and test scores in adolescents. Learn. Instr. 22, 368-375. doi: 10.1016/j.learninstruc.2012.02.003

Horn, J. L. (1965). A rationale and test for the number of factors in factor analysis. Psychometrika 30, 179-185. doi: 10.1007/BF02289447

Hospel, V., and Galand, B. (2016). Are both classroom autonomy support and structure equally important for students' engagement? A multilevel analysis. Learn. Instr. 41, 1-10. doi: 10.1016/j.learninstruc.2015.09.001

Hulleman, C. S., Kosovich, J. J., Barron, K. E., and Daniel, D. B. (2016). Making connections: replicating and extending the utility value intervention in the classroom. J. Educ. Psychol. 108, 374-391. doi: 10.1037/edu0000146

Jang, H., Reeve, J., and Deci, E. L. (2010). Engaging students in learning activities: it is not autonomy support or structure but autonomy support and structure. J. Educ. Psychol. 102, 588-600. doi: 10.1037/a0019682

Kiemer, K., Gröschner, A., Pehmer, A.-K., and Seidel, T. (2015). Effects of a classroom discourse intervention on teachers' practice and students' motivation to learn mathematics and science. Learn. Instr. 35, 94-103. doi: 10.1016/j. learninstruc.2014.10.003

Konold, T. (2016). A multilevel MTMM approach to estimating the influences of contextual factors on trait and informant-based method effects in assessments of school climate. J. Psychoeduc. Assess. (in press). doi: 10.1177/ 0734282916683286

Kunter, M., Klusmann, U., Baumert, J., Richter, D., Voss, T., and Hachfeld, A. (2013). Professional competence of teachers: effects on instructional quality and student development. J. Educ. Psychol. 105, 805-820. doi: 10.1037/a00 32583

Kusurkar, R. A., Croiset, G., and Ten Cate, T. J. (2011). Twelve tips to stimulate intrinsic motivation in students through autonomy-supportive classroom teaching derived from Self-Determination Theory. Med. Teach. 33, 978-982. doi: 10.3109/0142159X.2011.599896

Legault, L., Green-Demers, I., and Pelletier, L. (2006). Why do high school students lack motivation in the classroom? Toward an understanding of academic amotivation and the role of social support. J. Educ. Psychol. 98, 567-582. doi: 10.1037/0022-0663.98.3.567

León, J., and Liew, J. (2017). Profiles of adolescents' peer and teacher relatedness: differences in well-being and academic achievement across latent groups. Learn Individ. Differ. 54, 41-50. doi: 10.1016/j.lindif.2017.01.009

León, J., Núñez, J. L., and Liew, J. (2015). Self-determination and STEM education: effects of autonomy, motivation, and self-regulated learning on high school math achievement. Learn. Individ. Diff. 43, 156-163. doi: 10.1016/j.lindif.2015. 08.017

Levpuscek, M. P., Zupancic, M., and Socan, G. (2012). Predicting achievement in mathematics in adolescent students: the role of individual and social factors. J. Early Adolesc. 33, 523-551. doi: 10.1177/0272431612450949

Liew, J., Johnson, A. Y., Smith, T. R., and Thoemmes, F. (2011a). Parental expressivity, child physiological and behavioral regulation, and child adjustment: testing a three-path mediation model. Early Educ. Dev. 22, 549-573. doi: 10.1080/10409289.2010.481551

Liew, J., Xiang, P., Johnson, A. Y., and Kwok, O. (2011b). Effortful persistence and body mass as predictors of running achievement in children and youth: a longitudinal study effortful persistence as index of self-regulatory efficacy. J. Phys. Act. Health 8, 234-243.

Lipowsky, F., Rakoczy, K., Pauli, C., Drollinger-Vetter, B., Klieme, E., and Reusser, K. (2009). Quality of geometry instruction and its short-term impact on students' understanding of the Pythagorean Theorem. Learn. Instr. 19, 527-537. doi: 10.1016/j.learninstruc.2008.11.001

Liu, W. C., Wang, J. C. K., and Ryan, R. M. (2016a). Building Autonomous Learners. Singapore: Springer. doi: 10.1007/978-981-287-630-0

Liu, W. C., Wang, J. C. K., and Ryan, R. M. (2016b). "Understanding motivation in education: theoretical and practical considerations," in Building Autonomous Learners, eds C. John, J. C. K. Wang, and R. M. Ryan (Singapore: Springer), 1-8.

Longobardi, C., Prino, L. E., Marengo, D., and Settanni, M. (2016). Student-teacher relationships as a protective factor for school adjustment during the transition from middle to high school. Front. Psychol. 7:1988. doi: 10.3389/fpsyg.2016. 01988

Marsh, H. W., Craven, R. G., Hinkley, J. W., and Debus, R. L. (2003). Evaluation of the big-two-factor theory of academic motivation orientations: an evaluation of jingle-jangle fallacies. Multivariate Behav. Res. 38, 189-224. doi: 10.1207/ S15327906MBR3802

Marsh, H. W., and Roche, L. A. (1997). Making students' evaluations of teaching effectiveness effective. Am. Psychol. 52, 1187-1197. doi: 10.1037//0003-066x.52. 11.1187

McDonald, R. P. (1999). Test Theory: A Unified Treatment. Mahwah, NJ: Erlbaum.

McLean, L., and Connor, C. M. (2015). Depressive symptoms in third-grade teachers: relations to classroom quality and student achievement. Child Dev. 86, 945-954. doi: 10.1111/cdev.12344

McNeish, D. (2017). Thanks coefficient Alpha, we'll take it from here. Psychol. Methods (in press). doi: 10.1037/met0000144

Meder, B., and Gigerenzer, G. (2014). "Statistical thinking: no one left behind," in Probabilistic Thinking, eds G. Kaiser and B. Sriraman (New York, NY: Springer), 127-148.

Morin, A. J. S., Marsh, H. W., Nagengast, B., and Scalas, L. F. (2014). Double latent multilevel analyses of classroom climate: an illustration. J. Exp. Educ. 82, 143-167. doi: 10.1080/00220973.2013.769412 
Muthén, B. O., and Asparouhov, T. (2012). Bayesian SEM: a more flexible representation of substantive theory. Psychol. Methods 17, 313-335. doi: 10. 1037/a0026802

Ng, J. Y. Y., Lonsdale, C., and Hodge, K. (2011). The Basic Needs Satisfaction in Sport Scale (BNSSS): instrument development and initial validity evidence. Psychol. Sport Exerc. 12, 257-264. doi: 10.1016/j.psychsport.2010.10.006

Núñez, J. L., Fernández, C., León, J., and Grijalvo, F. (2015). The relationship between teacher's autonomy support and students' autonomy and vitality. Teach. Teach. 21, 191-202. doi: 10.1080/13540602.2014.928127

Núñez, J. L., and León, J. (2015). Autonomy support in the classroom: a review from the self-determination theory. Eur. Psychol. 20, 275-283. doi: 10.1027/ 1016-9040/a000234

Núñez, J. L., León, J., Grijalvo, F., and Martín-Albo, J. (2012). Measuring autonomy support in university students: the Spanish version of the learning climate questionnaire. Span. J. Psychol. 15, 1466-1472. doi: 10.5209/rev_SJOP.2012.v15. n3.39430

OECD (2010). The High Cost of Low Educational Performance. Paris: PISA, OECD Publishing.

OECD (2014). PISA 2012 Results: What Students Know and Can Do - Student Performance in Mathematics, Reading and Science. Paris: PISA, OECD Publishing. doi: 10.1787/9789264201118-en

Pintrich, P. R. (2004). A conceptual framework for assessing motivation and self-regulated learning in college students. Educ. Psychol. Rev. 16, 385-407. doi: 10.1007/s10648-004-0006-x

Pintrich, P. R., and de Groot, E. V. (1990). Motivational and self-regulated learning components of classroom academic performance. J. Educ. Psychol. 82, 33-40. doi: 10.1037//0022-0663.82.1.33

Pintrich, P. R., Smith, D. A. F., Garcia, T., McKeachie, W. J., and García, T. (1993). Reliability and predictive validity of the Motivated Strategies for Learning Questionnaire (MSLQ). Educ. Psychol. Meas. 53, 801-813. doi: 10. $1177 / 0013164493053003024$

Reeve, J., Vansteenkiste, M., Assor, A., Ahmad, I., Cheon, S. H., Jang, H., et al. (2014). The beliefs that underlie autonomy-supportive and controlling teaching: a multinational investigation. Motiv. Emot. 38, 93-110. doi: 10.1007/ s11031-013-9367-0

Revelle, W., and Zinbarg, R. E. (2009). Coefficients Alpha, Beta, Omega, and the glb: comments on Sijtsma. Psychometrika 74, 145-154. doi: 10.1007/s11336008-9102-z

Riconscente, M. M. (2014). Effects of perceived teacher practices on latino high school students' interest, self-efficacy, and achievement in mathematics. J. Exp. Educ. 82, 51-73. doi: 10.1080/00220973.2013.813358

Rjosk, C., Richter, D., Hochweber, J., Lüdtke, O., Klieme, E., and Stanat, P. (2014). Socioeconomic and language minority classroom composition and individual reading achievement: the mediating role of instructional quality. Learn. Instr. 32, 63-72. doi: 10.1016/j.learninstruc.2014.01.007

Roth, G., Assor, A., Kanat-Maymon, Y., and Kaplan, H. (2007). Autonomous motivation for teaching: how self-determined teaching may lead to selfdetermined learning. J. Educ. Psychol. 99, 761-774. doi: 10.1037/0022-0663.99. 4.761

Rothbart, M. K., Ellis, L. K., Rueda, M. R., and Posner, M. I. (2003). Developing mechanisms of temperamental effortful control. J. Pers. 71, 1113-1143. doi: 10.1111/1467-6494.7106009

Ruzek, E. A., Domina, T., Conley, A. M., Duncan, G. J., and Karabenick, S. A. (2014). Using value-added models to measure teacher effects on students' motivation and achievement. J. Early Adolesc. 35, 852-882. doi: 10.1177/ 0272431614525260

Ryan, R. M., and Deci, E. L. (2009). "Promoting self-determined school engagement: motivation, learning and well-being," in The Handbook of Motivation at School, eds K. R. Wentzel and A. Wigfield (New York, NY: Routledge), 171-196.

Ryan, R. M., and Powelson, C. L. (1991). Autonomy and relatedness as fundamental to motivation and education. J. Exp. Educ. 60, 49-66. doi: 10.1186/ 1472-6920-13-151

Sánchez-Pérez, N., Fuentes, L. J., Pina, V., López-López, J. A., and GonzálezSalinas, C. (2015). How do different components of effortful control contribute to children's mathematics achievement? Front. Psychol. 6:1383. doi: 10.3389/ fpsyg. 2015.01383
Seaton, M., Parker, P. D., Marsh, H. W., Craven, R. G., and Yeung, A. S. (2014). The reciprocal relations between self-concept, motivation and achievement: juxtaposing academic self-concept and achievement goal orientations for mathematics success. Educ. Psychol. 34, 49-72. doi: 10.1080/01443410.2013. 825232

Seidel, T., and Shavelson, R. J. (2007). Teaching effectiveness research in the past decade: the role of theory and research design in disentangling meta-analysis results. Rev. Educ. Res. 77, 454-499. doi: 10.3102/0034654307310317

Simões, F., and Alarcão, M. (2014). Mentors and teachers: testing the effectiveness of simultaneous roles on school performance from a basic psychological needs perspective. Instr. Sci. 42, 465-483. doi: 10.1007/s11251-013-9288-z

Simons, J., Willy, L., Soenens, B., and Ma, L. (2005). Examining the motivational impact of intrinsic versus extrinsic goal framing and autonomy-supportive versus internally controlling communication style on early adolescents $\hat{\mathrm{a}} €^{\mathrm{TM}}$ academic achievement. Child Dev. 76, 483-501. doi: 10.1111/j.1467-8624.2005. 00858.x

Skinner, E. A., and Belmont, M. J. (1993). Motivation in the classroom: reciprocal effects of teacher behavior and student engagement across the school year. J. Educ. Psychol. 85, 571-581. doi: 10.1037//0022-0663.85.4.571

Skinner, E. A., Kindermann, T. A., Connell, J. P., and Wellborn, J. G. (2009). "Engagement and disaffection as organizational constructs in the dynamics of motivational development," in Handbook of Motivation in School, eds K. R. Wentzel and A. Wigfield (Malwah, NJ: Erlbaum), 223-246.

Stefanou, C. R., Perencevich, K. C., Dicintio, M., and Turner, J. C. (2004). Supporting autonomy in the classroom: ways teachers encourage student decision making and ownership. Educ. Psychol. 39, 97-110. doi: 10.1207/ s15326985ep3902

Stroet, K., Opdenakker, M. C., and Minnaert, A. (2013). Effects of need supportive teaching on early adolescents' motivation and engagement: a review of the literature. Educ. Res. Rev. 9, 65-87. doi: 10.1016/j.edurev.2012.11.003

Stroet, K., Opdenakker, M. C., and Minnaert, A. (2015a). Need supportive teaching in practice: a narrative analysis in schools with contrasting educational approaches. Soc. Psychol. Educ. 18, 585-613. doi: 10.1007/s11218-015-9290-1

Stroet, K., Opdenakker, M. C., and Minnaert, A. (2015b). What motivates early adolescents for school? A longitudinal analysis of associations between observed teaching and motivation. Contemp. Educ. Psychol. 42, 129-140. doi: 10.1016/j. cedpsych.2015.06.002

Su, Y.-L., and Reeve, J. (2010). A meta-analysis of the effectiveness of intervention programs designed to support autonomy. Educ. Psychol. Rev. 23, 159-188. doi: 10.1007/s10648-010-9142-7

Taylor, I. M., and Ntoumanis, N. (2007). Teacher motivational strategies and student self-determination in physical education. J. Educ. Psychol. 99, 747-760. doi: 10.1037/0022-0663.99.4.747

Ten Cate, T. J., Kusurkar, R. A., and Williams, G. (2011). How self-determination theory can assist our understanding of the teaching and learning processes in medical education. AMEE guide No. 59. Med. Teach. 33, 961-973. doi: 10.3109/ 0142159X.2011.595435

Tessier, D., Sarrazin, P. G., and Ntoumanis, N. (2010). The effect of an intervention to improve newly qualified teachers' interpersonal style, students motivation and psychological need satisfaction in sport-based physical education. Contemp. Educ. Psychol. 35, 242-253. doi: 10.1016/j.cedpsych.2010. 05.005

Thapa, A., Cohen, J., Guffey, S., and Higgins-D’Alessandro, A. (2013). A review of school climate research. Rev. Educ. Res. 83, 357-385. doi: 10.3102/ 0034654313483907

Thorsen, C., and Cliffordson, C. (2012). Teachers' grade assignment and the predictive validity of criterion-referenced grades. Educ. Res. Eval. 18, 153-172. doi: 10.1080/13803611.2012.659929

Thurlings, M., Vermeulen, M., Bastiaens, T., and Stijnen, S. (2013). Understanding feedback: a learning theory perspective. Educ. Res. Rev. 9, 1-15. doi: 10.1016/j. edurev.2012.11.004

Turner, J. C., Christensen, A., Kackar-Cam, H. Z., Trucano, M., and Fulmer, S. M. (2014). Enhancing students' engagement: report of a 3-year intervention with middle school teachers. Am. Educ. Res. J. 51, 1195-1226. doi: 10.3102/ 0002831214532515

Valiente, C., Swanson, J., Lemery-Chalfant, K., and Berger, R. H. (2014). Children's effortful control and academic achievement: do relational peer victimization 
and classroom participation operate as mediators? J. Sch. Psychol. 52, 433-445. doi: $10.1016 /$ j.jsp.2014.05.005

Vansteenkiste, M., and Ryan, R. M. (2013). On psychological growth and vulnerability: basic psychological need satisfaction and need frustration as a unifying principle. J. Psychother. Integr. 23, 263-280. doi: 10.1037/a0032359

Vansteenkiste, M., Sierens, E., Goossens, L., Soenens, B., Dochy, F., Mouratidis, A., et al. (2012). Identifying configurations of perceived teacher autonomy support and structure: associations with self-regulated learning, motivation and problem behavior. Learn. Instr. 22, 431-439. doi: 10.1016/j.learninstruc.2012. 04.002

Veronneau, M.-H., Racer, K. H., and Dishion, T. J. (2014). The contribution of adolescent effortful control to early adult educational attainment. J. Educ. Psychol. 106, 730-743. doi: 10.1037/a0035831

Wagner, W., Göllner, R., Helmke, A., Trautwein, U., and Lüdtke, O. (2013). Construct validity of student perceptions of instructional quality is high, but not perfect: dimensionality and generalizability of domain-independent assessments. Learn. Instr. 28, 1-11. doi: 10.1016/j.learninstruc.2013.03.003

Wallace, T. L., Kelcey, B., and Ruzek, E. A. (2016). What can student perception surveys tell us about teaching? Empirically testing the underlying structure of the tripod student perception survey. Am. Educ. Res. J. 53, 1834-1868. doi: $10.3102 / 0002831216671864$

Wang, M.-T., Degol, J., and Ye, F. (2015). Math achievement is important, but task values are critical, too: examining the intellectual and motivational factors leading to gender disparities in STEM careers. Front. Psychol. 6:36. doi: 10.3389/ fpsyg.2015.00036

Wang, M.-T., and Eccles, J. S. (2013). School context, achievement motivation, and academic engagement: a longitudinal study of school engagement using a multidimensional perspective. Learn. Instr. 28, 12-23. doi: 10.1016/j learninstruc.2013.04.002

Wentzel, K. R. (2002). Are effective teachers like good parents? Teaching styles and student adjustment in early adolescence. Child Dev. 73, 287-301. doi: 10.1111/1467-8624.00406

Zee, M., Koomen, H. M., and Van der Veen, I. (2013). Student-teacher relationship quality and academic adjustment in upper elementary school: the role of student personality. J. Sch. Psychol. 51, 517-533. doi: 10.1016/j.jsp.2013.05.003

Zimmerman, B. J. (1990). Self-regulated learning and academic achievement: an overview. Educ. Psychol. 25, 3-17. doi: 10.1207/s15326985ep2501_2

Zimmerman, B. J. (2013). From cognitive modeling to self-regulation: a social cognitive career path. Educ. Psychol. 48, 135-147. doi: 10.1080/00461520.2013. 794676

Zimmerman, B. J., and Kitsantas, A. (2014). Comparing students' self-discipline and self-regulation measures and their prediction of academic achievement. Contemp. Educ. Psychol. 39, 145-155. doi: 10.1016/j.cedpsych.2014.03.004

Conflict of Interest Statement: The authors declare that the research was conducted in the absence of any commercial or financial relationships that could be construed as a potential conflict of interest.

Copyright (c) 2017 Leon, Medina-Garrido and Núñez. This is an open-access article distributed under the terms of the Creative Commons Attribution License (CC BY). The use, distribution or reproduction in other forums is permitted, provided the original author(s) or licensor are credited and that the original publication in this journal is cited, in accordance with accepted academic practice. No use, distribution or reproduction is permitted which does not comply with these terms. 